\title{
Parental Intermittent Claudication as a Risk Factor for Claudication in Adults
}

\author{
Scott G. Prushik, MDa, ${ }^{,}$Alik Farber, MDD, ${ }^{\mathrm{*}}$, Philimon Gona, $\mathbf{P h D}^{\mathrm{c}, \mathrm{d}}$, Peter Shrader, BA ${ }^{\mathrm{c}, \mathrm{e}}$, \\ Michael J. Pencina, PhD ${ }^{c, d}$, Ralph B. D’Agostino Sr, PhD ${ }^{c, d}$, and Joanne M. Murabito, MD \\ $\mathrm{ScM}^{\mathrm{d}, \mathrm{f}}$ \\ aDepartment of Vascular Surgery, University of Massachusetts, Worchester, MA, USA \\ bBoston University School of Medicine, Department of Vascular Surgery, Boston, MA, USA \\ 'Boston University, Department of Mathematics and Statistics, Boston, MA,USA \\ dNHLBl's Framingham Heart Study, Framingham, MA, USA \\ eNew England Research Institutes, Watertown, MA, USA \\ 'Boston University School of Medicine, Department of Medicine, Section of General Internal \\ Medicine, Boston, MA, USA
}

\section{Abstract}

Little is known about the familial aggregation of intermittent claudication (IC). Our objective was to examine whether parental IC increased adult offspring risk of IC independent of established cardiovascular risk factors. We evaluated Offspring cohort participants of the Framingham Heart Study (FHS) who were 30 years or older, cardiovascular disease (CVD) free, and had both parents enrolled in the FHS ( $\mathrm{n}=2970$ unique participants, 53\% women). Pooled proportional hazards regression was used to examine whether the 12 year risk for incident IC in offspring participants was associated with parental IC adjusting for age, sex, diabetes, smoking, systolic blood pressure, total cholesterol, high density lipoprotein (HDL) cholesterol, anti-hypertensive and lipid treatment. Among 909 person-exams in the parental IC history group and 5397 person-exams in the no parental IC history group there were 101 incident IC events ( 29 with parental IC history, 72 without parental IC history) during follow-up. Age and sex adjusted 12-year cumulative incidence rates per 1000 person-years were 5.08 (95\% CI: $2.74 ; 7.33)$ and 2.34 (95\% CI: $1.46 ; 3.19)$ in participants with and without parental IC history. Parental history of IC significantly increased the risk of incident IC in offspring (multivariable adjusted hazard ratio of 1.81, 95\% CI 1.14, 2.88). The hazard ratio was unchanged with adjustment for occurrence of CVD $(1.83,95 \%$ CI 1.15 , 2.91). In conclusion, IC in parents increases risk for IC in adult offspring independent of established risk factors. These data suggest a genetic component of peripheral artery disease and support future research into genetic causes.

(C) 2011 Excerpta Medica, Inc. All rights reserved.

Address for Correspondence and Reprint requests: Joanne M. Murabito MD ScM, 73 Mt Wayte Ave Suite \#2, Framingham MA 01702, murabito@bu.edu, Phone: (508) 935-3461, Fax: (508) 626-1262.

these authors contributed equally

Publisher's Disclaimer: This is a PDF file of an unedited manuscript that has been accepted for publication. As a service to our customers we are providing this early version of the manuscript. The manuscript will undergo copyediting, typesetting, and review of the resulting proof before it is published in its final citable form. Please note that during the production process errors may be discovered which could affect the content, and all legal disclaimers that apply to the journal pertain. 


\section{Keywords}

claudication; peripheral artery disease; risk factors; family history

\section{Introduction}

A National Institutes of Health consensus statement describes family history as being vital to patient care because it can uncover information about factors that contribute to the risk of developing common diseases, such as diabetes mellitus, stroke, cancer, and heart disease.(1) The occurrence of CVD in a parent or sibling confers an increased risk for CVD in middleaged adults that is distinct from traditional risk factors. $(2 ; 3)$ Parental occurrence of stroke is associated with a 3 fold increase in risk of offspring stroke.(4) However, little is known about the familial aggregation of PAD. Individuals whose siblings were diagnosed with premature PAD were shown to have an almost 3-fold increase in PAD.(5) Finally, early onset of symptomatic CVD is more common in first-degree relatives of individuals with premature PAD than in relatives of healthy individuals.(6) The latter 2 studies are limited by small sample size, examination of PAD prevalence rather than incidence, and inability to quantify the degree of familial aggregation of PAD that was independent of established risk factors. The Framingham Heart Study (FHS) affords the unique opportunity to study IC across two generations using prospectively collected data in a large community-based sample. The present study was undertaken to test the hypothesis that parental IC confers an increased risk of IC in adult offspring independent of established CVD risk factors.

\section{Methods}

The FHS is a prospective epidemiologic cohort study which was established in 1948 when 5209 residents of Framingham, Massachusetts, aged 28 to 62 years were enrolled. Members of the original cohort have undergone examinations every two years. In 1971, offspring of the original cohort $(n=3548)$ and spouses of the offspring $(n=1576)$ aged 5 to 70 years were enrolled into the Framingham Offspring Study.(7) The offspring cohort has undergone an examination about every 4 to 8 years. All participants have provided informed consent and all study protocols have been approved by the Institutional Review Board of Boston University School of Medicine.

Data from three offspring examinations (Figure 1), each with 12 years of follow-up, were pooled: Offspring exam 1 (1971 to 1975), 3 (1983 to 1987), and 6 (1995 to 1998). Follow up for the final examination ended in December 2007. Given the structure of follow up examinations in the offspring, we chose to study the 12 year incidence of IC in order to have a comparable length of non-overlapping follow-up after each baseline exam. All offspring participants who were $\geq 30$ years at the time of any of the three baseline examinations were eligible if both parents were enrolled in the original cohort and if the Offspring participant was free of CVD, and IC, at the time of the exam. There were 2970 unique subjects (1405 men) in our final study sample including 346 individuals with a parental history of IC and 2624 individuals with both parents free of IC. Parental IC was defined as the occurrence of IC in a parent prior to the offspring examination. Both parental IC events and incident IC events occurring in offspring were adjudicated by a panel of three senior investigators using the same previously established criteria. Investigators were blinded to parental IC status. All available information was used to determine the presence of IC including the standardized physician-administered IC questionnaire that was part of each routine FHS research clinic visit and if available records from office visits with the participants' personal health care provider, and hospital records pertaining to PAD.(8) The standardized physicianadministered questionnaire asked about the presence of calf and leg discomfort brought on 
by exertion, the relation of the discomfort to the rapidity of walking or uphill walking and whether the symptoms were relieved with rest. The final diagnosis of IC was based on clinical history only without confirmatory testing. At the more contemporary FHS examinations participants were queried about lower extremity revascularization procedures and all self-reports were validated with medical records.

At each offspring examination risk factors were directly measured and the occurrence of CVD was updated. Resting blood pressure was measured twice. Current smoking was defined as smoking one or more cigarettes per day in the year preceding the examination. Blood was drawn, in the fasting state, for total cholesterol, high density lipoprotein (HDL) cholesterol, and triglycerides. Diabetes was defined as a fasting glucose level of $126 \mathrm{mg} / \mathrm{dl}$ $(7.0 \mathrm{mmol} / \mathrm{L})$ or greater or the use of insulin or oral hypoglycemic agents. CVD was defined as any of the following events: myocardial infarction, coronary insufficiency, angina pectoris, stroke, transient ischemic attack, congestive heart failure, or cardiovascular death.

Follow-up time within each 12-year period was calculated as the time from each baseline visit date until the diagnosis date of IC for those participants who developed the disease and censored at the earliest of date of last contact, date of death, or end of the 12-year period for participants who did not develop the disease. Age and sex adjusted incidence rates and 95\% confidence intervals per 1000 person-years were calculated in each parental IC history group by dividing the number of IC events observed by the total person-years. Kaplan-Meier curves and the log-rank test were used to plot and to compare cumulative incidence rates. Pooled proportional hazards regression analyses were used to examine whether the 12 year risk for incident IC in offspring was associated with parental IC. This method of pooling person-examinations provides estimates of effect similar to a time-dependent Cox proportional hazards model.(9) Furthermore, this method allows us to update risk factors and parental IC at each examination. Hazard ratios and $95 \%$ confidence intervals were calculated with the reference group consisting of participants with no parental IC prior to the examination. Covariates used in the multivariable model included: age, sex, diabetes, current smoking, systolic blood pressure, anti-hypertensive treatment, total cholesterol, HDL cholesterol, and cholesterol lowering treatment. In secondary analyses we adjusted for the occurrence of CVD in the Offspring participants using two approaches. First we used Cox models in which CVD was entered as a time-dependent covariate; next follow-up time was censored when an offspring participant developed any CVD event to account for the fact that CVD increases the risk of IC. To assess the incremental predictive utility of parental IC history associated with incident IC in offspring, we calculated c-statistic for the model with clinical covariates alone and the full model with clinical covariates and parental IC history. $(10 ; 11)$ We assessed model calibration (i.e., concordance of observed risk and that predicted by the model with parental IC history) by calculating the Hosmer-Lemeshow chi-squared statistic for Cox models.(10;11) To evaluate if inclusion of parental IC history improved risk classification of participants, we calculated the enhanced "net reclassification improvement" (NRI) using an extension to survival analysis that employs Kaplan-Meier estimates of event probabilities at 12 years.(11) We used 12-year IC risk thresholds of less than 2\%, 2\% to 5\%, and greater than 5\% for the net reclassification improvement index. The NRI is used to assess how well a new marker "reclassifies" patients from one risk category to another. Since there are no previously established categories for the absolute risk of IC, we also assessed "categoryless" net reclassification improvement, which assesses any upward or downward reclassification; values greater than 0 correspond to improved reclassification. (12) We performed a secondary analysis defining incident events in Offspring as IC and or lower extremity revascularization. All statistical analyses were performed using SAS statistical software version 9 (SAS Institute, Cary, NC). Statistical significance was defined as a 2-tailed $\mathrm{P}$ value less than 0.05 . 


\section{Results}

The baseline characteristics of the offspring study sample are shown in Table 1. The group of participants with parental history of IC was older (mean age 49.9 years vs. 47.6 years, $\mathrm{p}<$. 0001) and, with the exception of current smoking, had significantly higher risk factor levels compared to the group of participants without a parental history of IC. Over the course of follow up there were 101 incident IC events (29 in participants with parental history of IC, 72 in participants with no parental history of IC). Age- and sex- adjusted 12-year cumulative incidence rates per 1000 person-years were 5.08 (95\% CI: 2.74; 7.33) in participants with parental history of IC and 2.34 (95\% CI: 1.46; 3.19) in participants with no parental history of IC (Log rank test $\mathrm{p}<0.0001$, Figure 2). Parental IC was associated with a significantly increased risk for incident IC in offspring (age- and sex- adjusted HR 2.29). The association was modestly attenuated but remained significant after adjustment for traditional risk factors (multivariable adjusted HR 1.81, 95\% CI 1.14, 2.88) (Table 2). The association was unchanged after further adjustment for interim CVD and the magnitude and significance of the effect of parental IC persisted in the analysis in which follow-up time was censored when the offspring participant developed an incident CVD event (Table 2). The addition of parental IC history to a multivariable model incorporating baseline covariates increased the already high C-statistic from 0.831 (95\% CI: $0.794,0.868$ ) to 0.837 (95\% CI: 0.801, 0.873). The two C-statistics were not statistically different $(\mathrm{p}=0.22)$. The model with parental IC history had excellent calibration (Hosmer-Lemeshow Chi-squared $=14.07 ; \mathrm{p}=0.20$ ). The category-based NRI was modest $(9.3 \%, 95 \%$ CI: $1.9 \%$ to $17.3 \%)$ and the category-free NRI was $34.5 \%$ (95\% CI: $15.5 \%$ to $55.6 \%$ ). The NRI estimates remained essentially unchanged with adjustment for occurrence of CVD entered as a time-dependent covariate, or in a model in which follow-up time was censored when a participant developed any CVD event. The association between parental IC and incident PAD defined as IC and or lower extremity revascularization ( $\mathrm{n}=114$ events) was very similar to the primary analysis (multivariableadjusted HR 1.76, 95\% CI 1.14, 2.72; further adjustment for CVD as a time-dependent covariate: HR 1.77, 95\% CI 1.15, 2.73; and censoring at first occurrence of CVD: HR 1.84, 95\% CI 1.13, 2.97 did not substantively change the association).

\section{Discussion}

In our community-based sample, parental IC confers a nearly 2 -fold increased risk for IC in adult offspring even after accounting for traditional risk factors and the interim occurrence of CVD. Parental history of IC is quite powerful in predicting IC in adult offspring, however the small improvement in C statistic and category-based NRI suggest modestly improved prediction of offspring IC beyond that of established risk factors. Our study suggests the presence of a genetic predisposition to IC. However, in addition to genetic factors, environmental and lifestyle factors that are shared within families can contribute to susceptibility to common diseases.(13) An individual's family history provides a readily accessible and important clinical tool to gain insight into an individual's risk of developing disease including PAD. Knowledge of one's family history has the potential to motivate positive lifestyle changes, enhance individual empowerment, and influence clinical decisions with respect to preventative interventions.(1) This may be especially important for PAD, a disease that is often undetected and undertreated by clinicians (14) and under appreciated by the lay public for its association with risk for myocardial infarction, stroke, and death. (15)

Little is known concerning the genetic determinants of PAD but family aggregation and heritability estimates suggest a significant genetic contribution.(16;17) Recently, Zintzaras et al created a publically available database that catalogs genetic association studies of PAD. (18) However, to date genetic associations for PAD remain inconclusive with no strongly 
replicated results.(19) The genetic susceptibility to PAD and CVD is likely conferred by multiple genes interacting with a variety of environmental factors. While PAD may share some genetic variants with CVD, there likely exists a set of genetic variants that are unique to PAD given the phenotypic diversity across the vascular system.(19)

Genome-wide association studies have identified a strongly replicated association between variants on chromosome 9p21 and MI and coronary artery disease.(20) The chromosome 9p21 locus appears to play a broad role in arterial disease as it is also associated with atherosclerotic stroke (21), vascular stiffness(22), and cerebral and abdominal aortic aneurysm. $(23 ; 24)$ The chromosome 9 p21 locus was associated with clinically diagnosed PAD however, the relation was no longer present when coronary artery disease cases were removed from the sample.(24) Recently this locus was reported to be associated with a higher prevalence of PAD and lower mean ABI level in older adults from three populationbased samples that was independent of risk factors and persisted even after removal of individuals with myocardial infarction.(25) The genome-wide association approach successfully identified genetic variants on chromosome $15 \mathrm{q} 24$ for nicotine dependence that conferred risk for PAD.(26) Thus, the genetic variants identified appear to influence risk for PAD through shared biologic mechanisms for CVD and smoking related behaviors.

Additionally, in a recent study of 1,292 patients with abdominal aortic aneurysms, the A allele of rs7025486 on chromosome 9q33 was found to be associated with abdominal aortic aneurysm and PAD.(27) No association was found between this gene and CVD risk factors suggesting there is an independent genetic predisposition.(27)

Using a murine hindlimb ischemia model of PAD, Dokun, et al. identified genetic influences on PAD disease severity.(28) Further work is needed to elucidate the genes responsible for the association as well as their human orthologs. One study, using microarray analysis of femoral artery specimens, elucidated over 400 genes that are either up or down regulated in patients with severe atherosclerosis.(29) Another similar study demonstrated that many of the genes involved in atherosclerosis are also involved in lipid synthesis and immune function pathways.(30) Clinical investigation that leads to the elucidation of the genetic basis of PAD may provide potential targets for future focused gene therapies.

Several strengths and limitations of the present study merit comment. The FHS is a large, community based sample with data collected prospectively in both parents and offspring. Symptoms of IC were adjudicated by a panel of senior investigators using well established criteria, and the risk factors were directly measured, rather than obtained by self report from the participants, which could be subject to misclassification. The majority of FHS participants are of white, European ancestry, limiting the generalizability of the results to individuals of other race/ethnic backgrounds. The diagnosis of IC is based on symptoms alone without confirmatory testing thus some of the participants with IC in this study may not have PAD. Conversely, only about $50 \%$ of individuals with PAD have leg pain symptoms. Risk factors used for adjustment in the multivariable models come from single occasion measurement and may not represent an assessment of lifetime risk factor exposure. Hence it is possible that the effect of parental history of IC on personal risk for IC may be over-estimated. Residual confounding may be present in that parental history may reflect low social class, passive smoking, diet or sedentary behaviors that we are not able to account for in our study.

\section{Acknowledgments}

This work was supported by the National Heart, Lung and Blood Institute's Framingham Heart Study (N01HC-25195). 


\section{Reference List}

1. Berg AO, Baird MA, Botkin JR, Driscoll DA, Fishman PA, Guarino PD, Hiatt RA, Jarvik GP, Millon-Underwood S, Morgan TM, Mulvihill JJ, Pollin TI, Schimmel SR, Stefanek ME, Vollmer WM, Williams JK. National Institutes of Health State-of-the-Science Conference Statement: Family History and Improving Health. Ann Intern Med. 2009; 151(12):872-877. [PubMed: 19884615]

2. Lloyd-Jones DM, Nam BH, D'Agostino RB Sr, Levy D, Murabito JM, Wang TJ, Wilson PW, O'Donnell CJ. Parental cardiovascular disease as a risk factor for cardiovascular disease in middleaged adults: a prospective study of parents and offspring. JAMA. 2004; 291(18):2204-2211. [PubMed: 15138242]

3. Murabito JM, Pencina MJ, Nam BH, D'Agostino RB Sr, Wang TJ, Lloyd-Jones D, Wilson PW, O'Donnell CJ. Sibling cardiovascular disease as a risk factor for cardiovascular disease in middleaged adults. JAMA. 2005; 294(24):3117-3123. [PubMed: 16380592]

4. Seshadri S, Beiser A, Pikula A, Himali JJ, Kelly-Hayes M, Debette S, DeStefano AL, Romero JR, Kase CS, Wolf PA. Parental occurrence of stroke and risk of stroke in their children: the Framingham study. Circulation. 2010; 121(11):1304-1312. [PubMed: 20212282]

5. Valentine RJ, Guerra R, Stephan P, Scoggins E, Clagett GP, Cohen J. Family history is a major determinant of subclinical peripheral arterial disease in young adults. J Vasc Surg. 2004; 39(2):351356. [PubMed: 14743135]

6. Valentine RJ, Verstraete R, Clagett GP, Cohen JC. Premature cardiovascular disease is common in relatives of patients with premature peripheral atherosclerosis. Arch Intern Med. 2000; 160(9): 1343-1348. [PubMed: 10809039]

7. Kannel WB, Feinleib M, McNamara PM, Garrison RJ, Castelli WP. An investigation of coronary heart disease in families. The Framingham offspring study. Am J Epidemiol. 1979; 110(3):281-290. [PubMed: 474565]

8. Murabito JM, D'Agostino RB, Silbershatz H, Wilson WF. Intermittent claudication. A risk profile from The Framingham Heart Study. Circulation. 1997; 96(1):44-49. [PubMed: 9236415]

9. D'Agostino RB, Lee ML, Belanger AJ, Cupples LA, Anderson K, Kannel WB. Relation of pooled logistic regression to time dependent Cox regression analysis: the Framingham Heart Study. Stat Med. 1990; 9(12):1501-1515. [PubMed: 2281238]

10. Pencina MJ, D'Agostino RB. Overall $\mathrm{C}$ as a measure of discrimination in survival analysis: model specific population value and confidence interval estimation. Stat Med. 2004; 23(13):2109-2123. [PubMed: 15211606]

11. Pencina MJ, D'Agostino RB Sr, D'Agostino RB Jr, Vasan RS. Evaluating the added predictive ability of a new marker: from area under the ROC curve to reclassification and beyond. Stat Med. 2008; 27(2):157-172. [PubMed: 17569110]

12. Pencina MJ, D'Agostino RB Sr, Steyerberg EW. Extensions of net reclassification improvement calculations to measure usefulness of new biomarkers. Stat Med. 2011; 30(1):11-21. [PubMed: 21204120]

13. Cupples LA. Family study designs in the age of genome-wide association studies: experience from the Framingham Heart Study. Curr Opin Lipidol. 2008; 19(2):144-150. [PubMed: 18388694]

14. Hirsch AT, Criqui MH, Treat-Jacobson D, Regensteiner JG, Creager MA, Olin JW, Krook SH, Hunninghake DB, Comerota AJ, Walsh ME, McDermott MM, Hiatt WR. Peripheral arterial disease detection, awareness, and treatment in primary care. JAMA. 2001; 286(11):1317-1324. [PubMed: 11560536]

15. Hirsch AT, Murphy TP, Lovell MB, Twillman G, Treat-Jacobson D, Mohler ER, Creager MA, Hobson RW, Robertson RM, Howard WJ, Schroeder P, Criqui MH. Gaps in public knowledge of peripheral arterial disease: the first national PAD public awareness survey. Circulation. 2007; 116(18):2086-2094. [PubMed: 17875966]

16. Kullo IJ, Turner ST, Kardia SL, Mosley TH Jr, Boerwinkle E, de Andrade M. A genome-wide linkage scan for ankle-brachial index in African American and non-Hispanic white subjects participating in the GENOA study. Atherosclerosis. 2006; 187(2):433-438. [PubMed: 16280126]

17. Murabito JM, Guo CY, Fox CS, D'Agostino RB. Heritability of the ankle-brachial index: the Framingham Offspring study. Am J Epidemiol. 2006; 164(10):963-968. [PubMed: 16928729] 
18. Zintzaras E, Zdoukopoulos N. A field synopsis and meta-analysis of genetic association studies in peripheral arterial disease: The CUMAGAS-PAD database. Am J Epidemiol. 2009; 170(1):1-11. [PubMed: 19435865]

19. Knowles JW, Assimes TL, Li J, Quertermous T, Cooke JP. Genetic susceptibility to peripheral arterial disease: a dark corner in vascular biology. Arterioscler Thromb Vasc Biol. 2007; 27(10): 2068-2078. [PubMed: 17656669]

20. Schunkert H, Gotz A, Braund P, McGinnis R, Tregouet DA, Mangino M, Linsel-Nitschke P, Cambien F, Hengstenberg C, Stark K, Blankenberg S, Tiret L, Ducimetiere P, Keniry A, Ghori MJ, Schreiber S, EL Mokhtari NE, Hall AS, Dixon RJ, Goodall AH, Liptau H, Pollard H, Schwarz DF, Hothorn LA, Wichmann HE, Konig IR, Fischer M, Meisinger C, Ouwehand W, Deloukas P, Thompson JR, Erdmann J, Ziegler A, Samani NJ. Repeated replication and a prospective metaanalysis of the association between chromosome 9p21.3 and coronary artery disease. Circulation. 2008; 117(13):1675-1684. [PubMed: 18362232]

21. Gschwendtner A, Bevan S, Cole JW, Plourde A, Matarin M, Ross-Adams H, Meitinger T, Wichmann E, Mitchell BD, Furie K, Slowik A, Rich SS, Syme PD, MacLeod MJ, Meschia JF, Rosand J, Kittner SJ, Markus HS, Muller-Myhsok B, Dichgans M. Sequence variants on chromosome 9p21.3 confer risk for atherosclerotic stroke. Ann Neurol. 2009; 65(5):531-539. [PubMed: 19475673]

22. Bjorck HM, Lanne T, Alehagen U, Persson K, Rundkvist L, Hamsten A, Dahlstrom U, Eriksson P. Association of genetic variation on chromosome 9p21.3 and arterial stiffness. J Intern Med. 2009; 265(3):373-381. [PubMed: 19019192]

23. Thompson AR, Golledge J, Cooper JA, Hafez H, Norman PE, Humphries SE. Sequence variant on 9 p21 is associated with the presence of abdominal aortic aneurysm disease but does not have an impact on aneurysmal expansion. Eur J Hum Genet. 2009; 17(3):391-394. [PubMed: 18854858]

24. Helgadottir A, Thorleifsson G, Magnusson KP, Gretarsdottir S, Steinthorsdottir V, Manolescu A, Jones GT, Rinkel GJ, Blankensteijn JD, Ronkainen A, Jaakelainen JE, Kyo Y, Lenk GM, Sakalihasan N, Kostulas K, Gottsater A, Flex A, Stefansson H, Hansen T, Andersen G, Weinsheimer S, Borch-Johnsen K, Jorgensen T, Shah SH, Quyyumi AA, Granger CB, Reilly MP, Austin H, Levey AI, Vaccarino V, Palsdottir E, Walters GB, Jonsdottir T, Snorradottir S, Magnusdottir D, Gudmundsson G, Ferrell RE, Sveinbjornsdottir S, Hernesniemi J, Niemela M, Limet R, Andersen K, Sigurdsson G, Benediktsson R, Verhoeven EL, Tejink JA, Grobbee DE, Rader DJ, Collier DA, Pedersen O, Pola R, Hillert J, Lindblad B, Valdimarsson EM, Magnadottir HB, Wijmenga C, Tromp G, Baas AF, Ruigrok YM, van Rij AM, Kuivaniemi H, Powell JT, Matthiasson SE, Gulcher JR, Thorgeirsson G, Kong A, Thorsteinsdottir U, Stefansson K. The same sequence variant on 9p21 associates with myocardial infarction, abdominal aortic aneurysm and intracranial aneurysm. Nat Genet. 2008; 40(2):217-224. [PubMed: 18176561]

25. Cluett C, McDermott MM, Guralnik J, Ferrucci L, Bandinelli S, Miljkovic I, Zmuda JM, Li R, Tranah G, Harris T, Rice N, Henley W, Frayling TM, Murray A, Melzer D. The 9p21 myocardial infarction risk allele increases risk of peripheral artery disease in older people. Circ Cardiovasc Genet. 2009; 2(4):347-353. [PubMed: 20031606]

26. Thorgeirsson TE, Geller F, Sulem P, Rafnar T, Wiste A, Magnusson KP, Manolescu A, Thorleifsson G, Stefansson H, Ingason A, Stacey SN, Bergthorsson JT, Thorlacius S, Gudmundsson J, Jonsson T, Jakobsdottir M, Saemundsdottir J, Olafsdottir O, Gudmundsson LJ, Bjornsdottir G, Kristjansson K, Skuladottir H, Isaksson HJ, Gudbjartsson T, Jones GT, Mueller T, Gottsater A, Flex A, Aben KK, de Vegt F, Melders PF, Isla D, Vidal MJ, Asin L, Saez B, Murilla L, Blondal T, Kolbeinsson H, Stefansson JG, Hansdottir I, Runarsdottir V, Pola R, Lindblad B, van Rij Am, Dieplinger B, Haltmayer M, Mayordomo JI, Kiemeney LA, Matthiasson SE, Oskarsson H, Tyrfingsson T, Gudbjartsson DF, Gulcher JR, Jonsson S, Thorsteinsdottir U, Kong A, Stefansson K. A variant associated with nicotine dependence, lung cancer and peripheral arterial disease. Nature. 2008; 452(7187):638-642. [PubMed: 18385739]

27. Gretarsdottir S, Baas AF, Thorleifsson G, Holm H, den Heijer M, de Vries JP, Kranendonk SE, Zeebregts CJ, van Sterkenburg SM, Geelkerken RH, van Rij AM, Williams MJ, Boll AP, Kostic JP, Jonasdottir A, Jonasdottir A, Walters GB, Masson G, Sulem P, Saemundsdottir J, Mouy M, Magnusson KP, Tromp G, Elmore JR, Sakalihasan N, Limet R, Defraigne JO, Ferrell RE, Ronkainen A, Ruigrok YM, Wijmenga C, Grobbee DE, Shah SH, Granger CB, Quyyumi AA, Vaccarino V, Patel RS, Zafari AM, Levey AI, Austin H, Girelli D, Pignatti PF, Oliveri O, 
Martinelli N, Malerba G, Trabetti E, Becker LC, Becker DM, Reilly MP, Rader DJ, Mueller T, Dieplinger B, Haltmayer M, Urbonavicius S, Lindblad B, Gottsater A, Gaetani E, Pola R, Wells P, Roger M, Forgie M, Langlois N, Corral J, Vicente V, Fontcuberta J, Espana F, Grarup N, Jorgensen T, Witte DR, Hansen T, Pedersen O, Aben KK, de Graaf J, Holewijn S, Folkersen L, Franco-Cereceda A, eriksson P, Collier DA, Stefansson H, Steinthorsdottir V, Rafnar T, Valdimarsson EM, Magnadottir HB, Sveinbjornsdottir S, olafsson I, Magnusson MK, Palmason R, Haraldsdottir V, Andersen K, Onundarson PT, Thorgeirsson G, Kiemeney LA, Powell JT, Carey DJ, Kuivaniemi H, Lindholt JS, Jone GT, KOng A, Blankensteijn JD, Matthiasson SE, Thorsteinsdottir U, Stefansson K. Genome-wide association study identifies a sequence variant within the DAB2IP gene conferring susceptibility to abdominal aortic aneurysm. Nat Genet. 2010; 42(8):692-697. [PubMed: 20622881]

28. Dokun AO, Keum S, Hazarika S, Li Y, Lamonte GM, Wheeler F, Marchuk DA, Annex BH. A quantitative trait locus (LSq-1) on mouse chromosome 7 is linked to the absence of tissue loss after surgical hindlimb ischemia. Circulation. 2008; 117(9):1207-1215. [PubMed: 18285563]

29. Fu S, Zhao H, Shi J, Abzhanov A, Crawford K, Ohno-Machado L, Zhou J, Du Y, Kuo WP, Zhang J, Jiang M, Jin JG. Peripheral arterial occlusive disease: global gene expression analyses suggest a major role for immune and inflammatory responses. BMC Genomics. 2008; 9:369. [PubMed: 18673543]

30. Evans DC, Sileshi B, Zakaria AM, Giangiacomo D, Manson RJ, Lawson JH. Genomic modeling of atherosclerosis in peripheral arterial disease and its variant phenotype in patients with diabetes. Vascular. 2008; 16(4):225-235. [PubMed: 18845104] 
Framingham Heart Study Offspring Examinations:

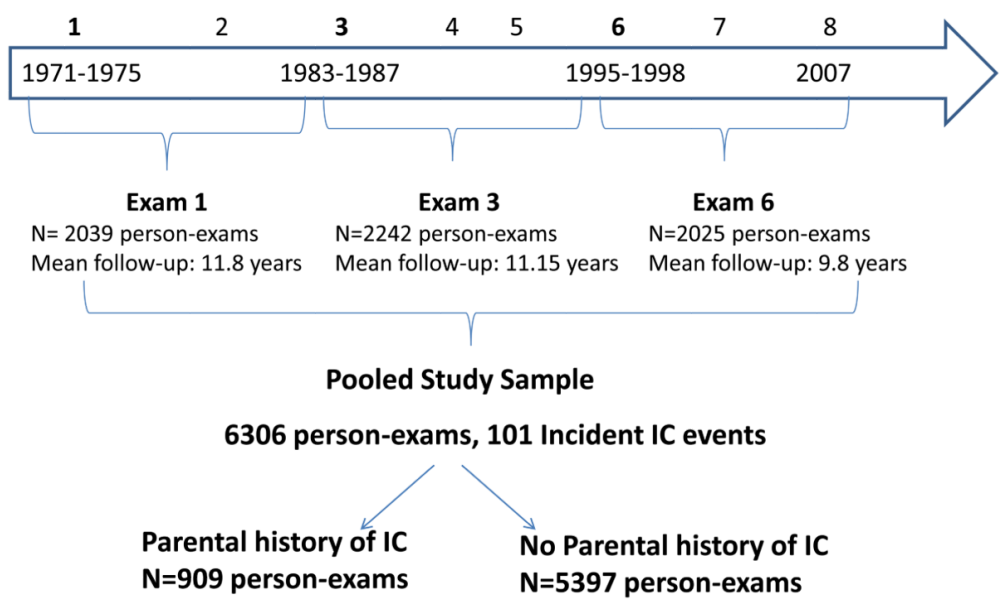

Figure 1.

Study Sample: Data from 3 baseline exams each with 12 years of follow-up were pooled. 


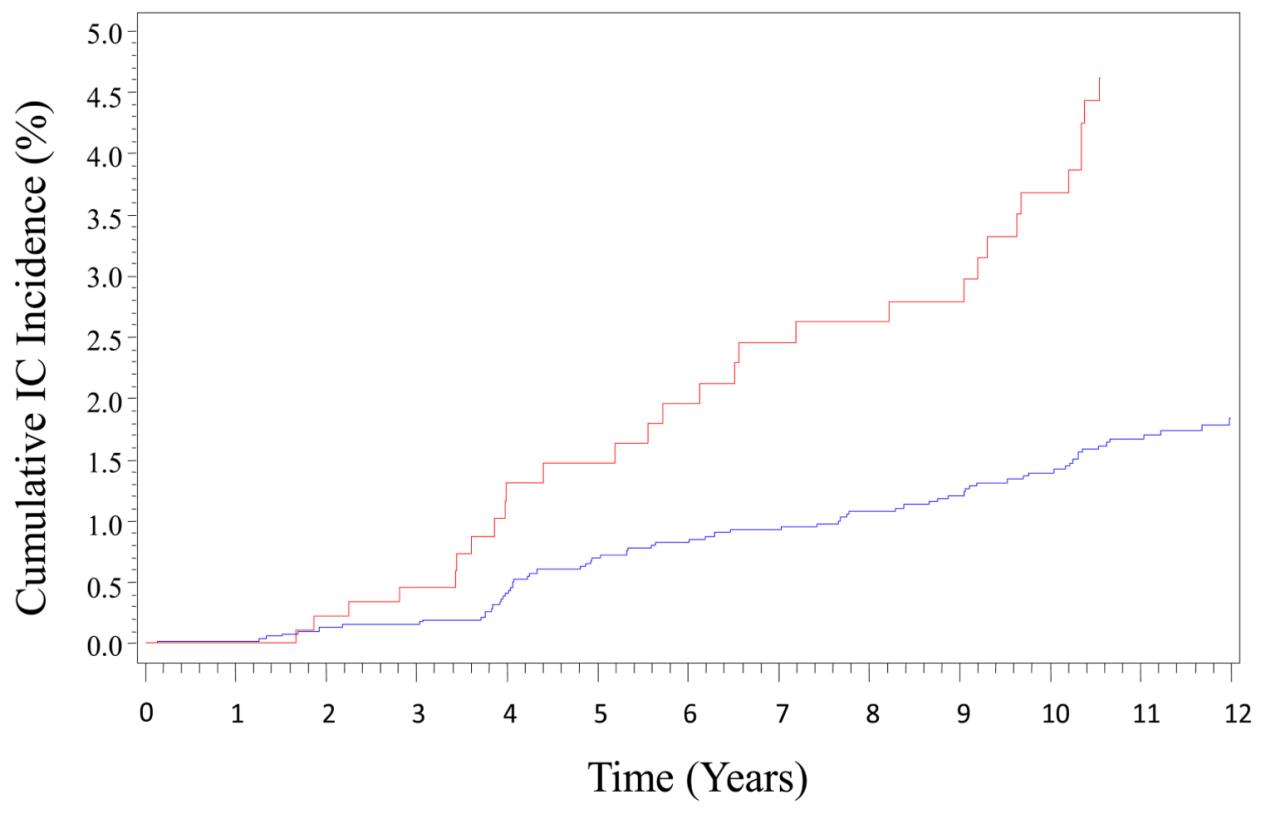

No Parental History of IC — Parental History of IC

Figure 2.

Age and Sex Adjusted Cumulative Incidence per 1000 Person-Years of Intermittent Claudication 
Table 2

12 Year Risk of Intermittent Claudication by Parental Occurrence of Intermittent Claudication

\begin{tabular}{|c|c|c|c|c|}
\hline Model & Hazard Ratio & $95 \%$ Confidence & Interval & p value \\
\hline Age and Sex Adjusted & 2.29 & 1.49 & 3.54 & 0.0002 \\
\hline Multivariable (MV) Adjusted ${ }^{*}$ & 1.81 & 1.14 & 2.88 & 0.01 \\
\hline $\mathrm{MV}+\mathrm{CVD}^{\dagger}$ (Time Dependent) & 1.83 & 1.15 & 2.91 & 0.01 \\
\hline $\mathrm{MV}+$ Censor for Interim $\mathrm{CVD}^{\dagger}$ & 1.92 & 1.16 & 3.19 & 0.01 \\
\hline
\end{tabular}

* Multivariable model adjusted for the following covariates: age, sex, diabetes, current cigarette smoking, systolic blood pressure, anti-hypertensive treatment, total cholesterol, HDL cholesterol, and lipid lowering treatment.

${ }^{\dagger} \mathrm{CVD}=$ cardiovascular disease 